\title{
Gender differences in coerced patients with schizophrenia
}

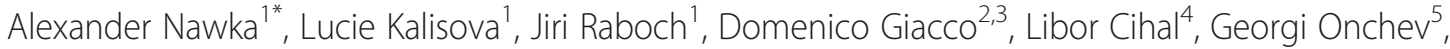 \\ Anastasia Karastergiou ${ }^{6}$, Zahava Solomon $^{7}$, Andrea Fiorillo ${ }^{3}$, Valeria Del Vecchio ${ }^{3}$, Algirdas Dembinskas $^{8}$, \\ Andrzej Kiejna ${ }^{9}$, Petr Nawka ${ }^{10}$, Francisco Torres-Gonzales ${ }^{11}$, Stefan Priebe ${ }^{2}$, Lars Kjellin ${ }^{12,13}$ \\ and Thomas W Kallert ${ }^{14,15,16}$
}

\begin{abstract}
Background: Despite the recent increase of research interest in involuntary treatment and the use of coercive measures, gender differences among coerced schizophrenia patients still remain understudied. It is well recognized that there are gender differences both in biological correlates and clinical presentations in schizophrenia, which is one of the most common diagnoses among patients who are treated against their will. The extent to which these differences may result in a difference in the use of coercive measures for men and women during the acute phase of the disease has not been studied.
\end{abstract}

Methods: 291 male and 231 female coerced patients with schizophrenia were included in this study, which utilized data gathered by the EUNOMIA project (European Evaluation of Coercion in Psychiatry and Harmonization of Best Clinical Practice) and was carried out as a multi-centre prospective cohort study at 13 centers in 12 European countries. Sociodemographic and clinical characteristics, social functioning and aggressive behavior in patients who received any form of coercive measure (seclusion and/or forced medication and/or physical restraint) during their hospital stay were assessed.

Results: When compared to the non-coerced inpatient population, there was no difference in sociodemographic or clinical characteristics across either gender. However coerced female patients did show a worse social functioning than their coerced male counterparts, a finding which contrasts with the non-coerced inpatient population. Moreover, patterns of aggressive behavior were different between men and women, such that women exhibited aggressive behavior more frequently, but men committed severe aggressive acts more frequently. Staff used forced medication in women more frequently and physical restraint and seclusion more frequently with men.

Conclusions: Results of this study point towards a higher threshold of aggressive behavior the treatment of women with coercive measures. This may be because less serious aggressive actions trigger the application of coercive measures in men. Moreover coerced women showed diminished social functioning, and more importantly more severe symptoms from the "excitement/hostile" cluster in contrast to coerced men. National and international recommendation on coercive treatment practices should include appropriate consideration of the evidence of gender differences in clinical presentation and aggressive behaviors found in inpatient populations.

Keywords: Gender, Schizophrenia, Involuntary treatment, Seclusion, Restraint, Forced medication, Aggressive behavior, EUNOMIA project

\footnotetext{
* Correspondence: a.nawka@gmail.com

${ }^{1}$ Department of Psychiatry, First Faculty of Medicine, Charles University,

Prague, Czech Republic

Full list of author information is available at the end of the article
}

\section{Biomed Central}

(c) 2013 Nawka et al.; licensee BioMed Central Ltd. This is an open access article distributed under the terms of the Creative Commons Attribution License (http://creativecommons.org/licenses/by/2.0), which permits unrestricted use, distribution, and reproduction in any medium, provided the original work is properly cited. 


\section{Background}

Since the advent of psychiatry as a profession, coercive measures have been used in the treatment of mental illness. Although there has been a recent increase of interest in involuntary treatment [1-5], gender differences among coerced patiets still remain understudied [6,7].

It is well recognized that gender differences have an impact on mental health in many disorders, and in particular on the course of schizophrenia [8]. Neurodevelopmental $[9,10]$ and neuropathological theories $[11,12]$, and the estrogen protection hypothesis $[13,14]$ have all been proposed as explanations for how gender differences develop in schizophrenia. Taken together, these three theoretical frameworks can integrate a wide variety of findings of gender differences in schizophrenia, with compelling evidence existing for all approaches $[15,16]$.

The way that gender modifies the phenotypic expression of schizophrenia is a consistent theme in the literature, and a number of gender differences have been reported [17]. Schizophrenia onset occurs at a significantly earlier age in male patients in comparison to female patients $[15,18,19]$. Male patients are more severely impaired in ratings of negative symptoms [18,20,21], cognitive impairment [15], express less severe positive symptoms [18] and are more likely to show severe deterioration over time [19]. Female patients are likely to have more severe positive symptoms [19], with more hallucinations [22], persecutory delusions [15], affective symptoms [15,19] and greater number of suicide attempts [22]. Women also show lower pre-morbid cognitive performance [23] and the course of the illness is considerably less severe [24]. In contrast to research summarized above, several studies have shown no gender difference in symptom severity [25], neurocognitive functioning $[25,26]$, delusional symptoms [22], positive symptoms [20], minor physical anomalies [15] or neurological soft signs [15].

The course of the illness is more favorable in females in the short- [27] and middle-term [15], with females manifesting better social functioning [20,24,28] and having fewer hospitalizations with shorter inpatient stays [24,29]. Women with schizophrenia are also more often married [25,30], employed [25] and live independently [25]. Males have poorer premorbid functioning [15,22,31], are frequently unemployed, live alone $[19,22]$ have poorer social networks [22] and poorer functional outcome [18]. Only one study, conducted in Australia, found no gender difference in social functioning [31]. The duration of untreated psychosis has been found to be similar for both genders [22].

Psychotic disorders, including schizophrenia, are the most common diagnosis among patients who are involuntarily admitted to psychiatric hospitals and treated against their will [32]. Aggressive behavior and poor insight play a major role in involuntary (re)hospitalization [33]. Ries et al. [34] found that $65 \%$ of a population of acutely admitted patients with schizophrenia were males. Man with schizophrenia have been found to commit severe acts of violence more frequently than woman $[35,36]$. However, less severe aggressive behavior, for example verbal threats, has been found to be more frequent among women $[37,38]$. Other studies have found no gender differences in aggressive behavior among patients with schizophrenia $[39,40]$.

It is possible that gender differences in the clinical presentation, and biological correlates of severe mental illness may result in a different use of coercive measures during the acute phases of psychiatric disorders and in hospitalizations for men and women $[41,42]$. Studies have found that physical restraint was used more often with male patients, while forced medication and seclusion was used more often with female patients [41]. Male gender is also associated with higher rates of seclusion [43], restraint [44] and psychiatric intensive care [45]. Other studies have found that physical restraint was more often used with females [42] and female patients were more frequently secluded than their male counterparts [46]. No gender differences in the use of mechanical restraint have been found in studies conducted in the USA [47], or Finland, where all the forms of coercive measures studied were equally commonly applied to male and female patients $[48,49]$. Approval rates of coercive methods however, are greater by male than by female patients $[45,50]$. This finding was also replicated in the EUNOMIA study, where females expressed more negative views on whether involuntary admission was right or wrong [5].

The aim of this study was to investigate whether there are gender differences among coerced patients with schizophrenia in 12 European countries, in regards to the sociodemographical and clinical characteristics, social functioning, aggressive behavior, and the use of coercive measures.

\section{Methods}

This study utilized data gathered by the EUNOMIA project (European Evaluation of Coercion in Psychiatry and Harmonization of Best Clinical Practice). The main objective of the EUNOMIA project was to analyze the existing national variations in coercive psychiatric treatment within the European region, along with its influencing factors and outcomes. The characteristics of the individual centers, including the number of hospital beds per 100000 inhabitants, the number of staff per bed and the average number of beds per room were assessed by the European Service Mapping Schedule, vision 3 [51] and a special instrument describing the characteristics of hospitals [52] which were published in our previous article [7]. A more detailed description of the EUNOMIA project methodology might be found elsewhere [1-3,5,7]. 
The EUNOMIA project was carried out as a multicentre prospective cohort study at 13 centers in 12 European countries: Dresden, Germany; Sofia, Bulgaria; Prague, Czech Republic; Thessaloniki, Greece; Tel Aviv, Israel; Naples, Italy; Vilnius, Lithuania; Wroclaw, Poland; Michalovce, Slovak Republic; Granada and Malaga, Spain; Orebro, Sweden; and East London, United Kingdom; and each participating center recruited involuntarily admitted patients between July 2003 and December 2005. Patients who fulfilled the following criteria were included in the analysis: diagnosis of schizophrenia (i.e., F20.0-F20.9 diagnosis according to ICD-10 as established by psychiatric reports within the first seven days of admission); patient has received any form of coercive measure (seclusion and/or forced medication and/or physical restraint) during their hospital stay, age between 18 and 65 years; ability to sign an informed (written) consent form; not admitted to a special unit for only forensic or intoxicated patients; not included in the study before (repeated admissions during the study period); not transferred to a participating clinic from another hospital; and having a permanent living address in the catchment area of the participating hospitals.

Patients who fulfilled the criteria were assessed by researchers at three different points in time: within the first seven days of admission (T1), at 4 weeks or at discharge (T2), and at 3 months after admission (T3), independent of the patient's current living situation. Baseline socio-demographic characteristics and diagnosis of the patient according to ICD-10 [53] (WHO 1998) were obtained from medical records. These included data on age, gender, civil status, living situation, employment situation, previous psychiatric hospitalizations and previous involuntary hospitalizations. As an indicator of clinical functioning, symptom levels were assessed on the 24-item version of the Brief Psychiatric Rating Scale (BPRS) [54], which ranges from 24 to 168, with 168 indicating the maximum symptom severity. Global Assessment of Functioning scale (GAF) [55] was used as an indicator of global social functioning. This scale constitutes axis V of the Diagnostic and Statistical Manual for Mental Disorders 4th edition (DSM-IV) [56] and assesses patient's social occupational and psychological functioning in a hypothetical continuum of 1 to 100 points, which is divided in 10 ranges of 10 points, although a single score that represents patient's level of functioning is obtained. All researchers were trained to use both scales. Inter-rater reliability for BPRS scale was assessed throughout the project (videotaped interview on the international level and with personal interviews on the national level) and an inter-rater reliability with interclass correlation coefficient of 0.78 was achieved. As for the training on GAF scale, 72 GAF vignettes were jointly rated by researchers that had received first a local training session and then a common international video training session (in English). The GAF inter-rater reliability for the whole training process was good with an interclass correlation coefficient of 0.74 . The Modified Overt Aggression Scale (MOAS), a widely used aggression scale with documented reliability and validity, was used to evaluate violent behavior for the duration of hospitalization. The scale has four categories of aggressive behavior (verbal aggression, aggression against property, auto-aggression, and physical aggression) [57]. Data concerning details of each application of coercive measures during the first 4 weeks of hospitalization or up to his/her discharge were gathered using a special 16-item questionnaire designed by the EUNOMIA group for the purpose of this study [7]. Coercive measures were defined as follows: 1) seclusion: the involuntary placement of an individual locked in a room alone, which may be set up especially for this purpose; 2) restraint: fixing at least one of the patient's limbs with a mechanical device or being held by a staff member for longer than $15 \mathrm{mi}$ nutes; and 3) forced medication: activities using restraint or strong psychological pressure (involving at least three staff members) to administer medication against the patient's will. Informed consent was obtained from all patients in this study after they were provided a complete description of the study. The national or regional review boards of the participating centers approved the study:

Research Ethics Committee, Medical University Sofia, Sofia, Bulgaria

The Ethics Committee of the General Teaching Hospital, Prague, Czech Republic

Ethics committee at the Faculty of Medicine at Dresden University of Technology, Dresden, Germany

Scientific Board of the Psychiatric Hospital of Thessaloniki, Thessaloniki, Greece

The Tel Aviv University IRB-Helsinki Committee, Tel Aviv, Israel

Ethical Committee of the Second University of Naples, Naples, Italy

Lithuanian Bioethics Committee, Vilnius, Lithuania

Commission of Bioethics at Wroclaw Medical University, Wroclaw, Poland

Ethical Committee of the Michalovce Psychiatric Hospital, Michalovce, Slovak Republic

Ethical Committee (Comité Ético) of University Hospital of San Cecilio. Granada, Spain

Research Ethics Committee of Örebro University Hospital, Örebro, Sweden

East London and The City Research Ethics Committee, London, UK

All statistical analyses were performed using SPSS version 17.0. T-test were performed to identify differences 
in socio-demographic factors between male and female patients. Differences between the groups in categorized background variables were assessed by chi-square analysis or, where appropriate, Fisher's exact tests. Correlation analysis and binary logistic regression were used for evaluation of how clinical characteristics, social characteristics and aggressive behavior were associated with gender. Logistic regression was used to estimate bivariate and adjusted association ratios for the dichotomous sex outcome categories. The candidate explanatory variables for a multiple regression were screened with uni-variate ordinal logistic regression. A main effect multivariable model was applied. Chi square test, Mann Whitney test, $t$-test were used to assess bivariate associations.

\section{Results}

Initially 1284 involuntary patients with schizophrenia were identified and of those final sample of coerced patients recruited in this study included 291 male and 231 female patients (total $=522 ; 55.8 \%$ vs. $44.2 \%$ ). $74.6 \%$ males and $64.0 \%$ females were patients with paranoid type of schizophrenia (F20.0). Patients with residual type of schizophrenia (F20.5) were the second largest group with $21.2 \%$ being women and $12.0 \%$ men. Undifferentiated type of schizophrenia (F20.3) accounted for $12.1 \%$ female and $8.6 \%$ male patients. Other types of schizophrenia: disorganized (F20.1); catatonic (F20.2); and other or unspecified schizophrenia types (F20.8 and F20.9) together represented only $4.8 \%$ of male, and $2.7 \%$ of female patients.

Female patients were significantly older $(41.1 \pm 10.8)$ than their male counterparts $(35.7 \pm 10.8)(\mathrm{p}<.05)$. Men were significantly more likely to be single $(77,0 \%$ vs. $41.2 \%$ ) while women were more likely to be married (30.3\% vs. $14.4 \%)$, divorced (22.2\% vs. $8.6 \%$ ) or widowed $(6.3 \%$ vs. $0 \%)$ ( $\mathrm{p}<.001)$. Female patients lived on their own significantly more often than male patients $(70.5 \%$ vs $46.1 \%)$. Almost half of male patients (48.4\%) reported living with their family/partner/friend, compared to only $26.7 \%$ of women $(\mathrm{p}<.001)$. Only $1.4 \%$ male and female patients lived in social institutions and the proportion of homeless was also very low (2.4\% males and $0.9 \%$ females). Male patients were significantly more likely to be unemployed (41.0\% vs. $29.2 \%$ ), but the numbers of those partially or fully employed (20.0\% vs. $19.6 \%)$ did not differ among genders. The biggest proportion of both genders, however, was on social welfare $(33.1 \%$ males and 43.0\% females).

There was no significant difference in respect to the past hospitalizations. About one-quarter of male patients and one-fifth of female patients had been admitted for the first time, and over three-quarters from both genders had been re-hospitalized. No significant difference among genders was found in respect to the past involuntary hospitalizations $\left(X^{2}=0.12, \mathrm{df}=1, \mathrm{p}=.73\right)$, but due to partial data availability no reliable proportions could be calculated. The BPRS total score, as an indicator of overall severity of symptoms, was significantly higher for female patients $(58.9 \pm 14.5$ vs. $54.6 \pm 14.0)(\mathrm{p}=.004)$ at T1. When performing an in depth analysis of individual items of BPRS several gender differences were apparent. Female patients scored significantly higher on several items, as follows. From the "positive cluster" [58]: hallucinations $(3.15 \pm 2.0$ vs. $2.80 \pm 1.8)(\mathrm{p}<.001)$; bizarre behavior (3.28 \pm 1.7 vs. $2.80 \pm 1.7)(\mathrm{p}<.001)$; conceptual disorganization $(2.57 \pm 1.6$ vs. $2.27 \pm 1.5)(\mathrm{p}<.001)$. From the "negative cluster": emotional withdrawal $(2.37 \pm$ 1.4 vs. $2.10 \pm 1.3)(\mathrm{p}<.001)$. Finally, from the "activation/ manic cluster": uncooperativeness $(2.29 \pm 1.6$ vs. $2.03 \pm$ 1.5) ( $<$ < .001); and motor hyperactivity (2.51 \pm 1.7 vs. $1.94 \pm 1.3)(\mathrm{p}<.001)$. Male patients did not score significantly higher on any of the individual items. A similar pattern of results to those found for BPRS were observed when comparing GAF scores as measures of global social functioning, suggesting more severe impairment in women. Male patients scores were significantly higher $(30.5 \pm$ 12.7 vs. $26.2 \pm 12.8)(\mathrm{p}<.001)$, indicating better social performance (Table 1). Table 2 shows bivariate and adjusted association for the main effect model of independent variables on gender categories. Clinical characteristics among coerced patients, according to BPRS subscales discriminate to a certain level between genders. More severe psychopathology in the "positive psychotic" subscale is associated with the male category, and "active/manic" and "negative psychotic" subscales with the female category. Overall global functioning also discriminated between sex categories, showing higher scores for men category.

More than two-thirds of both groups, men and women, have developed aggressive behavior during the first four weeks after admission (79.6\% females and $71.7 \%$ males). When assessing aggressive behavior simply by counting average MOAS scores for both groups, no significant difference was found (females $5.20 \pm 5.61$ vs. males $5.62 \pm$ 6.80) $(\mathrm{p}=.462)$. Women were more likely to show aggressive behaviors but with a lesser intensity (total MOAS score 1 to 7 ) (50.2\% vs. $40.2 \%)$ and men were found to be more severely aggressive when counting only those who scored 8 or higher in MOAS (14.47 \pm 5.61 vs. $12.34 \pm$ 4.97) $(\mathrm{p}=.01)$ (Table 3$) .373$ incidents were recorded of coercive measures being applied to 231 women and 573 to 291 men during the first four weeks of the hospitalization. The most frequently used coercive measure was forced medication (80.7\%), followed by physical restraint (57.1\%) and seclusion (10.7\%). Women were more likely to receive forced medication (87.9\% vs. 74.9\%) (odds ratio (OR) 2.4, 95\% confidence interval 1.51-3.90), whereas men were more likely to be physically restrained $(66.2 \%$ vs. $45.5 \%)$ $(\mathrm{OR}=2.4, \mathrm{CI} 1.66-3.67)$ or secluded $(17.2 \%$ vs. $2.6 \%)$ $(\mathrm{OR}=7.8, \mathrm{CI} 3.27-18.50)(\mathrm{p}<.001)$. No significant 
Table 1 Socio-demographic, clinical and social functioning characteristics of the sample at the baseline

\begin{tabular}{|c|c|c|c|c|}
\hline & $\begin{array}{l}\text { Total sample } \\
\mathrm{N}=522 \text { (\%) }\end{array}$ & $\begin{array}{c}\text { Female } \\
N=231(\%)\end{array}$ & $\begin{array}{c}\text { Male } \\
\mathrm{N}=291(\%)\end{array}$ & $p$ \\
\hline Age (mean $\pm S D)$ & $38.1 \pm 11.1$ & $41.1 \pm 10.8$ & $35.7 \pm 10.8$ & t-test, $p<.001$ \\
\hline \multicolumn{5}{|l|}{ Type of schizophrenia } \\
\hline Paranoid schizophrenia & $365(70.0)$ & $148(64.0)$ & $217(74.6)$ & $X^{2}=14.441, d f=6, p=.025$ \\
\hline Psychiatric hospitalization in the past & $389(74.5)$ & $178(79.5)$ & $211(74.0)$ & $X^{2}=2.052, d f=1, p=.152$ \\
\hline \multicolumn{5}{|l|}{ Marital status } \\
\hline Single & $319(61.1)$ & $95(41.2)$ & $224(77.0)$ & $X^{2}=75.514, d f=3, p<.001$ \\
\hline \multicolumn{5}{|l|}{ Employment status } \\
\hline Unemployed & $186(35.6)$ & $67(29.2)$ & $119(41.0)$ & $X^{2}=24.969, d f=6, p<.001$ \\
\hline \multicolumn{5}{|l|}{ Housing situation } \\
\hline Live on their own & $311(59.6)$ & $205(70.5)$ & $106(46.1)$ & $X^{2}=46.516, d f=5, p<.001$ \\
\hline BPRS total score (mean \pm SD) & $56.5 \pm 14.7$ & $58.9 \pm 14.5$ & $54.6 \pm 14.0$ & t-test, $p=.004$ \\
\hline GAF score (mean \pm SD) & $28.6 \pm 12.9$ & $26.2 \pm 12.8$ & $30.5 \pm 12.7$ & t-test, $p<.001$ \\
\hline
\end{tabular}

difference has been observed in the reasons that led to the use of coercive measures. From those provided in this study the most common reasons in both genders were "to prevent acts of violence against others" (56.0\% females and $59.0 \%$ males), followed by "worsening of condition" (31.4\% females and $27.8 \%$ males), and by "aggression against objects" (23.6\% vs. $18.5 \%$ ) (Table 4 ).

\section{Discussion}

This is the first international multicenter study which assessed gender differences across a large sample of coerced, involuntary treated patients with schizophrenia using standardized instruments. A number of pertinent findings can be drawn from our results: 1) across neither gender do coerced patients differ in sociodemographic or clinical characteristics from the non-coerced inpatient population; 2) coerced female patients show a worse social functioning than their male counterparts, which is in contrast to the non-coerced inpatient population; 3) patterns of aggressive behavior are different between men and women; women exhibit aggressive behavior more frequently, but men commit severe aggressive acts

Table 2 Logistic regression analysis of effects on gender categories

\begin{tabular}{|c|c|c|c|c|}
\hline \multirow{2}{*}{$\begin{array}{l}\text { Independent } \\
\text { variables }\end{array}$} & \multicolumn{2}{|c|}{ Bivariate associations } & \multicolumn{2}{|c|}{ Main effects model } \\
\hline & $O R$ & $95 \% \mathrm{Cl}$ & $O R$ & $95 \% \mathrm{Cl}$ \\
\hline Positive psychotic & $0.96^{*}$ & $0.93-0.99$ & $1.06^{*}$ & $1.01-1.12$ \\
\hline Suspiciousness/hostility & $0.95^{*}$ & $0.91-0.99$ & NS & \\
\hline Active/manic & $0.92^{*}$ & $0.89-0.96$ & $0.95^{*}$ & 0.9-0.99 \\
\hline Depression/anxiety & NS & & NS & \\
\hline Negative psychotic & $0.94^{*}$ & $0.91-0.97$ & $0.95^{*}$ & 0.9-0.99 \\
\hline Baseline GAF & $1.02^{*}$ & $1.01-1.04$ & $1.03^{*}$ & $1.01-1.05$ \\
\hline
\end{tabular}

more frequently. These gender differences in behavior may lead, along with "cultural factors" to 4) different patterns in the use of coercive measures among genders, where forced medication is the preferred method for women, while physical restraint and seclusion is used more frequently for men.

Males accounted for $55.8 \%$ of the patients and females for $44.2 \%$, which closely replicates the findings from a study of 1755 involuntary admitted patients in the USA (57.8 vs. 42.2) [32] and a study of 2222 patients in Denmark (63.6\% vs. 36.4\%) [59]. In Salize's report the percentage of compulsory admitted male patients varied between 50\% in Sweden and 69\% in France [60].

The study sample consisted mainly patients with paranoid schizophrenia (with slight prevalence of men) and residual schizophrenia (with slight prevalence of women). The finding that majority of people within the residual subtype of schizophrenia were women is in contrast with studies reporting a larger number of men evolving into residual schizophrenia, most likely because of greater frequency of negative symptoms and multiple admissions [61]. It is possible that the age difference between genders in our sample of involuntary admitted patients accounts for this difference, with women being older than men. Collectively, the other types of schizophrenia accounted for less than fifteen percent of our sample across both genders.

Consistent with the findings of other studies about the sociodemographic characteristics of "voluntary" treated patients with schizophrenia [22,25], our study found no major differences between voluntarily and involuntarily treated patients on sociodemographic variables. Coerced women were significantly older than men; they were more likely to be married, divorced or widowed; lived on their own more frequently; and were less frequently 
Table 3 Aggressive behavior observed during the hospital stay

\begin{tabular}{|c|c|c|c|c|}
\hline & & $\begin{array}{c}\text { Female } \\
\mathrm{N}=231(\%)\end{array}$ & $\begin{array}{c}\text { Male } \\
\mathrm{N}=291(\%)\end{array}$ & $p$ \\
\hline \multirow[t]{3}{*}{ Verbal aggression } & Total & $169(73.2)$ & $192(67.1)$ & $X^{2}=2.203, d f=1, p=.138$ \\
\hline & Severe & $18(7.8)$ & $60(21.0)$ & $X^{2}=17.346, d f=1, p<.001$ \\
\hline & Average score & $1.57 \pm 0.69$ & $1.88 \pm 1.00$ & $p=.015^{\#}$ \\
\hline \multirow[t]{3}{*}{ Aggression against property } & Total & 79 (34.2) & $72(25.5)$ & $X^{2}=4.593, d f=1, p=.032$ \\
\hline & Severe ${ }^{¥}$ & $7(3.0)$ & $26(9.2)$ & $X^{2}=8.082, d f=1, p=.004$ \\
\hline & Average score & $1.5 \pm 0.77$ & $2.0 \pm 0.96$ & $p<.001^{\#}$ \\
\hline \multirow[t]{3}{*}{ Auto-aggression } & Total & $25(10.8)$ & $34(11.8)$ & $X^{2}=.123, d f=1, p=.726$ \\
\hline & Severe & $5(2.2)$ & $12(4.2)$ & $X^{2}=1.622, d f=1, p=.203$ \\
\hline & Average score & $1.76 \pm 0.97$ & $2.32 \pm 1.01$ & $p=.023^{\#}$ \\
\hline \multirow[t]{3}{*}{ Physical aggression } & Total & $95(41.3)$ & $115(39.8)$ & $X^{2}=.122, d f=1, p=.727$ \\
\hline & Severe & $10(4.4)$ & $21(7.3)$ & $X^{2}=1.943, d f=1, p=.163$ \\
\hline & Average score & $1.47 \pm 0.74$ & $1.66 \pm 0.84$ & $p=.09^{\#}$ \\
\hline \multirow{2}{*}{\multicolumn{2}{|c|}{ MOAS total score 1-7 (mean \pm SD) }} & $116(50.2)$ & $117(40.2)$ & $p=.58^{\#}$ \\
\hline & & $3.18 \pm 1.92$ & $3.13 \pm 2.17$ & \\
\hline \multicolumn{2}{|c|}{ MOAS total score 8 or higher (mean $\pm S D$ ) } & $67(29.0) 12.34 \pm 4.97$ & $83(28.5) 14.47 \pm 5.61$ & $p=.01^{\#}$ \\
\hline \multicolumn{2}{|l|}{ MOAS total score $($ mean $\pm S D)$} & $5.20 \pm 5.61$ & $5.62 \pm 6.80$ & $p=.462^{\#}$ \\
\hline
\end{tabular}

¥scores 3 or 4 on respective MOAS items.

\#Mann-Whitney test.

unemployed. Coerced men were significantly more likely to be single; lived more frequently with their families, partners or friends; and were more frequently unemployed. Half of all patients of both genders were on social welfare. The proportion of the homeless psychotic patients who have been treated involuntarily was very low across both genders, which contrasts with findings from a US study, which found the proportion of homeless people in their sample to be ten times higher [62]. The chronicity of the psychotic illness was clearly associated with the likelihood of receiving coercive measures. More than three- quarters of all patients in our sample were re-hospitalized and the vast majority of women and men had already experienced involuntary hospitalization. Overall, female patients showed more severely impaired clinical functioning in comparison to men. Women scored higher than men on measures of several individual positive symptoms such as hallucinations and bizarre behavior, which is in line with other studies on schizophrenia populations $[15,19,22]$. However male gender was associated with overall higher scores on the "positive psychotic" subscale. Furthermore, coerced women were not more severely delusional than

Table 4 Coercive measures used in involuntary treated psychotic patients and the reasons for their use

\begin{tabular}{|c|c|c|c|c|}
\hline & & $\begin{array}{c}\text { Female } \\
\mathrm{N}=231(\%)\end{array}$ & $\begin{array}{c}\text { Male } \\
\mathrm{N}=291(\%)\end{array}$ & $\mathrm{p}$ \\
\hline \multirow[t]{3}{*}{ Type of coercive measure used } & Forced medication & $203(87.9)$ & $218(74.9)$ & $x^{2}=13.871, d f=1, p<.001$ \\
\hline & Physical restraint & $105(45.5)$ & $193(66.3)$ & $X^{2}=22.892, d f=1, p<.001$ \\
\hline & Seclusion & $6(2.6)$ & $50(17.2)$ & $X^{2}=28.602, d f=1, p<.001$ \\
\hline Total number of coercive measures applied & & $N=373$ & $N=573$ & $x^{2}=0.07, d f=1, p=.78$ \\
\hline \multirow[t]{6}{*}{$\begin{array}{l}\text { Reasons for the use of coercive measures } \\
\text { (chosen) }\end{array}$} & $\begin{array}{l}\text { Prevent acts of violence against her/ } \\
\text { himself }\end{array}$ & $74(19.8)$ & $95(16.6)$ & $X^{2}=1.636, d f=1, p=.224$ \\
\hline & $\begin{array}{l}\text { Severe danger or threat for his or her } \\
\text { health }\end{array}$ & $117(31.4)$ & $159(27.8)$ & $X^{2}=1.432, d f=1, p=.242$ \\
\hline & Inability to care for him-/herself & $34(9.1)$ & $62(10.8)$ & $X^{2}=.720, d f=1, p=.441$ \\
\hline & Prevent acts of violence against others & $209(56.0)$ & $338(59.0)$ & $X^{2}=.809, d f=1, p=.382$ \\
\hline & Prevent acts of violence against property & $88(23.6)$ & $106(18.5)$ & $X^{2}=3.595, d f=1, p=.059$ \\
\hline & Prevent escape & $49(13.1)$ & $88(15.4)$ & $X^{2}=.900, d f=1, p=.347$ \\
\hline
\end{tabular}


men and also did not score more highly on measures of affective symptoms, findings that converge with those described in other gender studies with non-coerced schizophrenia patients $[15,22]$. Coerced women did, however, score more highly than coerced men on the "negative symptom" emotional withdrawal, which differs to findings described elsewhere in non-coerced populations [18,20,21]. Women also scored more highly on two symptoms from the "excitement/hostile cluster"; uncooperativeness and motor hyperactivity, a fact that is mirrored in their more frequent involvement in aggressive behavior.

Our findings show differences in theclinical manifestations between the coerced population studied in this sample and other non-coerced schizophrenia populations. Further, and of greater interest, is the finding that coerced females showed a significantly worse social functioning than coerced men. This finding is of particular interest, as the majority of studies dealing with schizophrenia populations have reported the opposite finding, women showing higher social functioning than men $[20,24]$.

Aggressive behavior is very common among involuntarily admitted patients with schizophrenia. In this study female patients were involved in almost $80 \%$ in some kind of aggressive behavior, while men in slightly more than $70 \%$. Although this difference wasn't significant this finding may suggest a discrepancy with the literature on violence in out-patient psychiatric populations, where men are more violent than women. There are several possible factors that may explain this discrepancy. Firstly, assaults in men are associated with substance abuse, property crime and school truancy [63], factors that have little influence in the inpatients setting. Secondly, the presence of major mental disorders, including schizophrenia, increases the risk for violent offending relatively more in women than in men [64]. These results converge with those of studies showing that male overrepresentation vanishes in inpatient psychiatric populations [65]. In one study hospitalized women patients committed more assaults than their male counterparts, although men engaged in more fear-inducing behavior [66]. These results are consistent with our findings, where female patients were more frequently aggressive but with lesser intensity, whereas males were responsible for the most severe aggressive acts. These results have been observed for overall aggression as well as for verbal aggression and aggression against property items in MOAS. Interestingly, if only average scores for the aggression as measured by the MOAS instrument were used, no significant difference among genders would have been detected.

Although some studies have found no association between the risk of being coerced and gender $[48,49]$ in psychiatric populations, our study revealed several differences in the use of coercive measures. In European institutions men with schizophrenia were more than twice likely to end up being physically restrained than women, while the opposite pattern was true for the use of forced medication. One can only speculate on the reasons for such difference. One possible explanation for the higher use of forced medication among women may be the higher recorded rates of positive psychotic symptoms, especially considering positive psychotic symptoms are more likely to result in assaults in women than in men [63]. The most credible explanation for the more frequent use of physical restraint in men is that staff may feel more threatened by more serious aggressive behavior by men in comparison to the same aggressive behavior by women. Physical restraint may be seen as a more immediate way to control this aggression, and thus be considered a "safer" option to avoid aggressive acts against the hospital staff and other patients. However, as Lam et al. [65] conclude, there is an equal likelihood of injuries to staff members being caused by violent female patients as by violent male patients and thus signs of an elevated risk of violence should not be ignored on the basis of gender. The use of seclusion differed strongly across genders, with the likelihood of men being secluded being almost eight times higher than for women. It is possible that this large difference in the use of seclusion may again be explained by the more severe aggressive behavior observed in males (although it should be noted that seclusion was not used in all centers). Clearly cultural and local traditions and legislative practices will play an crucial role in how specific coercive measures are applied $[1,2]$. For example in the Netherlands involuntary medicating is highly restricted, while mechanical restraint is being forbidden in the UK [67]. When questioned about coercive measures for a Norwegian study, younger male patients reported, that they would prefer physical restraint and older male patients reported preferring seclusion over forced medication, whereas forced medication was preferred by female patients [41]. These findings were confirmed by a study conducted in the Netherlands, where female patients reported preferring forced medication over seclusion, while males preferred seclusion over forced medication [68]. In England physical restraint was strongly disapproved of by both genders [45], and female patients were more frequently subject to seclusion than their male counterparts and they were secluded more often but for shorter periods [46]. In a study by Georgieva et al., women reported that they had experienced coercive interventions as more burdensome than men [69], which may reflect their greater emotional responsiveness and lower average tolerance thresholds for painful stimuli [70]. In the future, instruments which measure the psychological impact of psychiatric coercive interventions, such as the "Coercion Experience Scale" [71] should be used to how compare 
different coercive interventions are experienced by patients. No significant difference was observed in the reasons given for the use of coercive measures. The most common reason reported for both genders was "to prevent acts of violence against others", followed by "worsening of condition", and by "aggression against objects". Auto-aggressive behavior accounted for less than onefifth of reasons given for the use of coercive measures, and surprisingly no gender differences were found either, which contrasts with other research, reporting women with schizophrenia as making a greater number of suicide attempts [22].

When interpreting the findings of this study some limitations must be taken into account. The recruitment process in this type of research is widely recognized as being very difficult (involving recruitment of severely ill patients with schizophrenia who are involuntary admitted and experiencing coercive measures) and therefore although only half of the eligible patients were interviewed, at rate that has been described as good for this type of study (acute settings with difficult-to-recruit patients) [72]. There is only limited data available to compare recruited and non-recruited patients for the United Kingdom, but analysis of the available data does not suggest a selection bias on the assessed characteristics [5]. Data on the use of coercive measures were based on available documentation and additional sources from the site personnel. The documentation of coercive measures in clinical records may differ between participating countries, and the number of unrecorded or unreported measures may also vary. However, all centers used a uniform and standardized protocol for data collection and the process of gathering all available information was rigorously applied. Although it was usual for several inpatient units in each country to be involved in this study [7], the data can't be fully generalizable because the variability in the use of coercive measures between hospitals in the same country is high [73].

\section{Conclusion}

A number of our findings have implications for the education of hospital staff, including the finding that the overall frequency of aggressive behaviors by schizophrenia patients is actually higher in women than it is in men, but the most severe aggressive behaviors are more frequent in men. Results of this study also point towards a higher threshold at which women are treated with the use of coercive measures. It is possible that this may be due to less serious aggressive actions by men triggering the application of coercive measures, as aggressive behavior by men is perceived as more threatening than the same behavior expressed by women. Moreover coerced women, in comparison with their non-coerced female counterparts and in contrast to coerced men, have diminished social functioning, and more importantly more severe symptoms from the "excitement/hostile" cluster.

Delineating gender differences in the use of coercive measures in patients with schizophrenia is important for developing targeted treatments [22,74]. Therefore national and international recommendation on coercive treatment practices should include appropriate consideration of the evidence of gender differences in clinical presentation and aggressive behaviors found in inpatient populations.

\section{Competing interests}

The authors declare that they have no competing interest.

\section{Authors' contributions}

JR, GO, AKa, ZS, AF, VDV, AD, AKi, PN FT, SP, LK and TWK participated in the design of the study. AN, LK, DG were involved in the data collection. AN, LK, DG and LC helped draft the manuscript and partially participated in the design of the study. LC performed the statistical analysis. All authors read and approved the final manuscript.

\section{Acknowledgments}

The authors gratefully acknowledge the valuable contribution of all the research workers involved in the data collection, the patients who participated and the staff of the participating hospitals. This study was funded by a grant from the European Commission (Quality of life and Management of Living Resources Programme, contract number QLG4-CT2002-01036), Czech Ministry of Education research grant MSM002160849, and research grants PRVOUK-P26/LF1/4 and PRVOUK-P03/LF1/9.

\section{Author details}

'Department of Psychiatry, First Faculty of Medicine, Charles University, Prague, Czech Republic. ${ }^{2}$ Unit for Social and Community Psychiatry, Queen Mary, University of London, London, UK. ${ }^{3}$ Department of Psychiatry, University of Naples, Naples, Italy. ${ }^{4}$ Central land office, Ministry of Agriculture, Prague, Czech Republic. ${ }^{5}$ Department of Psychiatry, Medical University of Sofia, Sofia, Bulgaria. ${ }^{6}$ Psychiatric Hospital, Thessaloniki, Greece. ${ }^{7}$ School of Social Work and Geha Mental Health Center, University of Tel Aviv, Tel Aviv, Israel. ${ }^{8}$ Psychiatric Clinic, Vilnius Mental Health Centre, University of Vilnius, Vilnius, Lithuania. ${ }^{9}$ Department of Psychiatry, Medical University, Wroclaw, Poland. ${ }^{10}$ Psychiatric private practice, Dresden, Germany. ${ }^{11}$ Department of Legal Medicine and Psychiatry, Medical Faculty, University of Granada, Granada, Spain. ${ }^{12}$ Psychiatric Research Centre, Orebro County Council, Orebro, Sweden. ${ }^{13}$ School of Health and Medical Sciences, Orebro University, Orebro, Sweden. ${ }^{14}$ Department of Psychiatry, Psychosomatic Medicine, and Psychotherapy, Park Hospital Leipzig, Leipzig, Germany. ${ }^{15}$ Soteria Hospital Leipzig, Leipzig, Germany. ${ }^{16}$ Department of Psychiatry and Psychotherapy, Faculty of Medicine, Dresden University of Technology, Dresden, Germany.

Received: 9 February 2013 Accepted: 1 October 2013

Published: 11 October 2013

\section{References}

1. Raboch J, Kalisova L, Nawka A, Kitzlerova E, Onchev G, Karastergiou A, Magliano L, Dembinskas A, Kiejna A, Torres-Gonzales F, Kjellin L, Priebe S, Kallert TW: Use of coercive measures during involuntary hospitalization: findings from ten European countries. Psychiatr Serv 2010, 61:1012-1017.

2. Fiorillo A, De Rosa C, Del Vecchio V, Jurjanz L, Schnall K, Onchev G, Alexiev S, Raboch J, Kalisova L, Mastrogianni A, Georgiadou E, Solomon Z, Dembinskas A, Raskauskas V, Nawka P, Nawka A, Kiejna A, Hadrys T, TorresGonzales F, Mayoral F, Björkdahl A, Kjellin L, Priebe S, Maj M, Kallert T: How to improve clinical practice on involuntary hospital admissions of psychiatric patients: suggestions from the EUNOMIA study. Eur Psychiatry 2011, 26:201-207.

3. Fiorillo A, Giacco D, De Rosa C, Kallert T, Katsakou C, Onchev G, Raboch J, Mastrogianni A, Del Vecchio V, Luciano M, Catapano F, Dembinskas A, Nawka P, Kiejna A, Torres-Gonzales F, Kjellin L, Maj M, Priebe S: Patient 
characteristics and symptoms associated with perceived coercion during hospital treatment. Acta Psychiatr Scand 2012, 125:460-467.

4. Giacco D, Fiorillo A, Del Vecchio V, Kallert T, Onchev G, Raboch J, Mastrogianni A, Nawka A, Hadrys T, Kjellin L, Luciano M, De Rosa C, Maj M, Priebe S: Caregivers' appraisals of patients' involuntary hospital treatment: European multicentre study. Br J Psychiatry 2012, 201:486-491.

5. Priebe S, Katsakou C, Glöckner M, Dembinskas A, Fiorillo A, Karastergiou A, Kiejna A, Kjellin L, Nawka P, Onchev G, Raboch J, Schuetzwohl M, Solomon Z, Torres-González F, Wang D, Kallert T: Patients' views of involuntary hospital admission after one and three months: a prospective study in eleven European countries. Br J Psychiatry 2010, 196:179-185.

6. Dressing $\mathrm{H}$, Salize $\mathrm{HJ}$ : Compulsory admission of mentally ill patients in European Union Member States. Soc Psychiatry Psychiatr Epidemiol 2004, 39:797-803.

7. Kallert TW, Glöckner M, Onchev G, Raboch J, Karastergiou A, Solomon Z, Magliano L, Dembinskas A, Kiejna A, Nawka P, Torres-González F, Priebe S, Kjellin L: The EUNOMIA project on coercion in psychiatry: study design and preliminary data. World Psychiatry 2005, 4:168-172.

8. Judd F, Armstrong S, Kulkarni J: Gender-sensitive mental health care. Australas Psychiatry 2009, 17:105-111.

9. Woods BT: Is schizophrenia a progressive neurodevelopmental disorder? Toward a unitary pathogenetic mechanism. Am J Psychiatry 1998, 155:1661-1670.

10. McDonald C, Murray RM: Early and late environmental risk factors for schizophrenia. Brain Res Rev 2000, 31:130-137.

11. Shenton ME, Dickey CC, Frumin M, McCarley RW: A review of MRI findings in schizophrenia. Schizophr Res 2001, 49:1-52.

12. James AC, Javaloyes A, James S, Smith DM: Evidence for nonprogressive changes in adolescent-onset schizophrenia: follow-up magnetic resonance imaging study. Br J Psychiatry 2002, 180:339-344.

13. Cohen RZ, Seeman MV, Gotowiec A, Kopala L: Earlier puberty as a predictor of later onset of schizophrenia in women. Am J Psychiatry 1999, 156:1059-1064.

14. Hoff AL, Kremen WS, Wieneke MH, Lauriello J, Blankfeld HM, Faustman WO, Csernansky JG, Nordahl TE: Association of estrogen levels with neuropsychological performance in women with schizophrenia. Am J Psychiatry 2001, 158:1134-1139.

15. Leung $A$, Chue P: Sex differences in schizophrenia, a review of the literature. Acta Psychiatr Scand 2000, 401:3-38.

16. Taylor R, Langdon R: Understanding gender differences in schizophrenia : a review of the literature. Curr Psychiatry Rev 2006, 2:255-265.

17. Goldstein JM: Sex differences in schizophrenia: epidemiology, genetics and the brain. Int Rev Psychiatry 1997, 9:399-408.

18. Moriarty PJ, Lieber D, Bennett A, White L, Parrella M, Harvey PD, Davis KL: Gender differences in poor outcome patients with lifelong schizophrenia. Schizophr Bull 2001, 27:103-113.

19. Tang YL, Gillespie CF, Epstein MP, Mao PX, Jiang F, Chen Q, Cai ZJ, Mitchell PB: Gender differences in 542 Chinese inpatients with schizophrenia. Schizophr Res 2007, 97:88-96.

20. Shtasel DL, Gur RE, Gallacher F, Heimberg C, Gur RC: Gender differences in the clinical expression of schizophrenia. Schizophr Res 1992, 7:225-231.

21. Morgan VA, Castle DJ, Jablensky AV: Do women express and experience psychosis differently from men? Epidemiological evidence from the Australian National Study of Low Prevalence (Psychotic) Disorder. Aust N Z J Psychiatry 2008, 42:74-82.

22. Thorup A, Petersen L, Jeppesen P, Ohlenschloeger J, Christensen T, Krarup $G$, Jorgensen P, Nordentoft M: Gender differences in young adults with first-episode schizophrenia spectrum disorders at baseline in the Danish OPUS study. J Nerv Ment Dis 2007, 195:396-405.

23. Weiser M, Reichenberg A, Rabinowitz J, Kaplan Z, Mark M, Nahon D, Davidson M: Gender differences in premorbid cognitive performance in a national cohort of schizophrenic patients. Schizophr Res 2000, 45:185-190.

24. Tamminga CA: Gender and schizophrenia. J Clin Psychiatry 1997, 58:33-37.

25. Andia AM, Zisook S, Heaton RK, Hesselink J, Jernigan T, Kuck J, Morganville J, Braff DL: Gender differences in schizophrenia. J Nerv Ment Dis 1995, 183:522-528.

26. Bozikas VP, Kosmidis MH, Peltekis A, Giannakou M. Nimatoudis I, Karavatos A, Fokas K, Garyfallos G: Sex differences in neuropsychological functioning among schizophrenia patients. Aust N Z J Psychiatry 2010, 44:333-341.

27. Usall J, Ochoa S, Araya S, Márquez M, NEDES Group: Gender differences and outcome in schizophrenia: a 2-year follow-up study in a large community sample. Eur Psychiatry 2003, 18:282-284.
28. Ochoa S, Usall J, Villalta-Gil V, Vilaplana M, Marquez M, Valdelomar M, Haro JM, NEDES Group: Influence of age at onset on social functioning in outpatients with schizophrenia. Eur J Psychiat 2006, 20:157-163.

29. Angermeyer MC, Kuhn L, Goldstein JM: Gender and the course of schizophrenia: differences in treated outcomes. Schizophr Bull 1990, 16:293-307.

30. Gureje O: Gender and schizophrenia: age at onset and sociodemographic attributes. Acta Psychiatr Scand 1991, 83:402-405.

31. Cotton SM, Lambert M, Schimmelmann BG, Foley DL, Morley Kl, McGorry PD, Conus P: Gender differences in premorbid, entry, treatment, and outcome characteristics in a treated epidemiological sample of 661 patients with first episode psychosis. Schizophr Res 2009, 114:17-24.

32. Sanguineti VR, Samuel SE, Schwartz SL, Robeson MR: Retrospective study of 2,200 involuntary psychiatric admissions and readmissions. Am J Psychiatry 1996, 153:392-396.

33. Steinert T, Wiebe C, Gebhardt RP: Aggressive behavior against self and others among first-admission patients with schizophrenia. Psychiatr Serv 1999, 50:85-90.

34. Ries RK, Russo J, Wingerson D, Snowden M, Comtois KA, Srebnik D, RoyByrne P: Shorter hospital stays and more rapid improvement among patients with schizophrenia and substance disorders. Psychiatr Serv 2000 51:210-215

35. Wessely SC, Castle D, Douglas AJ, Taylor PJ: The criminal careers of incident cases of schizophrenia. Psychol Med 1994, 24:483-502.

36. Elbogen $E B$, Johnson SC: The intricate link between violence and mental disorder: results from the national epidemiologic survey on alcohol and related conditions. Arch Gen Psychiatry 2009, 66:152-161.

37. Kiejna A, Janska-Skomorowska M, Baranowski P: Medical procedure with aggressive patients: experiences of the psychiatric clinic in Wroclaw. Psychiatr Pol 1993, 27:501-513.

38. Sebit MB, Siziya S, Acuda SW, Mhondoro E: Use of seclusion and restraint in psychiatric patients in Harare Hospital Psychiatric Unit, Zimbabwe: gender differences. Cent Afr J Med 1998, 44:277-280.

39. Hodgkinson PE, Mclvor L, Phillips M: Patient assaults on staff in a psychiatric hospital: a two-year retrospective study. Med Sci Law 1985, 25:288-294.

40. Miller RJ, Zadolinnyj K, Hafner RJ: Profiles and predictors of assaultiveness for different psychiatric ward populations. Am J Psychiatry 1993, 150:1368-1373.

41. Wynn R: Medicate, restrain or seclude? Strategies for dealing with violent and threatening behaviour in a Norwegian university psychiatric hospital. Scand J Caring Sci 2002, 16:287-291.

42. Beck NC, Durrett C, Stinson J, Coleman J, Stuve P, Menditto A: Trajectories of seclusion and restraint at a state psychiatric hospital. Psychiatr Serv 2008, 59:1027-1032.

43. Forquer S, Earle K, Way B, Banks S: Predictors of the use of restraint and seclusion in public psychiatric hospitals. Adm Policy Ment Health 1996, 23:527-532.

44. Knutzen M, Mjosund NH, Eidhammer G, Lorentzen S, Opjordsmoen S, Sandvik L, Friis S: Characteristics of psychiatric inpatients who experienced restraint and those who did not: a case-control study. Psychiatr Serv 2011, 62:492-497.

45. Whittington R, Bowers L, Nolan P, Simpson A, Neil L: Approval ratings of inpatient coercive interventions in a national sample of mental health service users and staff in England. Psychiatr Serv 2009, 60:792-798.

46. Mason T: Gender differences in the use of seclusion. Med Sci Law 1998, 38:2-9.

47. Smith GM, Davis RH, Bixler EO, Lin HM, Altenor A, Altenor RJ, Hardentstine BD, Kopchick GA: Pennsylvania State Hospital system's seclusion and restraint reduction program. Psychiatr Serv 2005, 56:1115-1122.

48. Kaltiala-Heino R, Korkeila J, Tuohimäki C, Tuori T, Lehtinen V: Coercion and restrictions in psychiatric inpatient treatment. Eur Psychiatry 2000, 15:213-219.

49. Keski-Valkama A, Sailas E, Eronen M, Koivisto AM, Lönnqvist J, Kaltiala-Heino $\mathrm{R}$ : Who are the restrained and secluded patients: a 15-year nationwide study. Soc Psychiatry Psychiatr Epidemiol 2010, 45:1087-1093.

50. Bowers $L$, van der Werf B, Vokkolainen A, Muir-Cochrane E, Allan T, Alexander J: International variation in attitudes to containment measures for disturbed psychiatric inpatients. Int J Nurs Stud 2007, 44:357-364.

51. Johnson S, Kuhlmann R, The EPCAT Group: The European Mapping Schedule (ESMS): development of an instrument for the description and classification of mental health services. Acta Psychiatr Scand 2000, 102:14-23. 
52. Salize HJ, Bullenkamp J, Alscher I, Wolf I: Quality assurance and documentation in the communal psychiatric combine (GPV) - a standardized procedure for regional recording and steering of community based mental health care [in German]. Psychiatr Prax 2000, 27:92-98.

53. World Health Organization: The ICD-10 Classification of Mental and Behavioural Disorders: Diagnostic Criteria for Research (DCR-10). Geneva: WHO; 1998.

54. Overall JE, Hollister LE, Pichot P: Major psychiatric disorder: a four dimensional model. Arch Gen Psychiatry 1967, 16:146-151.

55. Goldman HH, Skodol AE, Lave TR: Revising Axis V for DSM-IV: a review of measures of social functioning. Am J Psychiatry 1992, 149:1 148-1156.

56. American Psychiatric Association: DSM-IV. Diagnostic and Statistical Manual of Mental Disorders. Washington: APA; 1994.

57. Sorgi P, Ratey J, Knoedler DW, Markert RJ, Reichman M: Rating aggression in the clinical setting a retrospective adaptation of the Overt Aggression Scale: preliminary results. J Neuropsychiatr 1991, 3:552-556.

58. Velligan D, Prihoda T, Dennehy E, Biggs M, Shores-Wilson K, Crismon ML, Rush A, Miller A, Suppes T, Trivedi M, Kashner TM, Witte B, Toprac M, Carmody T, Chiles J, Shon S: Brief psychiatric rating scale expanded version: How do new items affect factor structure? Psychiatry Res 2005, 30(135):217-228.

59. Ohlenschlaeger J, Nordentoft M: Coercion in patients who at their first contact with the psychiatric services system were diagnosed within the schizophrenia-spectrum in Denmark. A register study. Nord J Psychiatry 2008, 62:77-81.

60. Salize HJ, Dreßing H, Peitz M: Compulsory Admission and Involuntary Treatment of Mentally III Patients Legislation and Practice in EU-Member States. http://europa.eu.int/comm/health/ph_projects/2000/promotion/ fp_promotion_2000_frep_08_en.pdf.

61. Beratis S, Gabriel J, Hoidas S: Gender differences in the frequency of schizophrenic subtypes in unselected hospitalized patients. Schizophr Res 1997, 28:239-244.

62. Craw J, Compton MT: Characteristics associated with involuntary versus voluntary legal status at admission and discharge among psychiatric inpatients. Soc Psychiatry Psychiatr Epidemiol 2006, 41:981-988.

63. Krakowski M, Czobor P: Gender differences in violent behaviors: relationship to clinical symptoms and psychosocial factors. Am J Psychiatry 2004, 161:459-465.

64. Hodgins S: Mental disorder, intellectual deficiency, and crime: evidence from a birth cohort. Arch Gen Psychiatry 1992, 49:476-483.

65. Lam JN, McNiel DE, Binder RL: The relationship between patients' gender and violence leading to staff injuries. Psychiatr Serv 2000, 51:1167-1170.

66. Binder RL, McNiel DE: The relationship of gender to violent behavior in acutely disturbed psychiatric patients. J Clin Psychiatry 1990, 51:110-114

67. Steinert $T$, Lepping $P$ : Legal provisions and practice in the management of violent patients. A case vignette study in 16 European countries. Eur Psychiatry 2009, 24:135-141.

68. Veltkamp E, Nijman H, Stolker JJ, Frigge K, Dries P, Bowers L: Patients' preferences for seclusion or forced medication in acute psychiatric emergency in the Netherlands. Psychiatr Serv 2008, 59:209-211. 69.

69. Georgieva I, Mulder CL, Whittington R: Evaluation of behavioral changes and subjective distress after exposure to coercive inpatient interventions. BMC Psychiatry 2012, 12:54.

70. Fillingim RB, King CD, Ribeiro-Dasilva MC, Rahim-Williams B, Riley JL: Sex gender, and pain: a review of recent clinical and experimental findings. J Pain 2009, 10:447-485.

71. Bergk J, Flammer E, Steinert T: "Coercion Experience Scale" (CES) validation of a questionnaire on coercive measures. BMC Psychiatry 2010, 10:5

72. Katsakou C, Priebe S: Outcomes of involuntary hospital admissions: a review. Acta Psychiatr Scand 2006, 114:232-241.

73. Martin V, Bernhardsgrutter R, Goebel R, Steinert T: The use of mechanical restraint and seclusion in patients with schizophrenia: a comparison of the practice in Germany and Switzerland. Clin Pract Epidemiol Ment Health 2007, 3:1-6.

74. Koster A, Lajer M, Lindhardt A, Rosenbaum B: Gender differences in first episode psychosis. Soc Psychiatry Psychiatr Epidemiol 2008, 43:940-946.

\section{Submit your next manuscript to BioMed Central and take full advantage of:}

- Convenient online submission

- Thorough peer review

- No space constraints or color figure charges

- Immediate publication on acceptance

- Inclusion in PubMed, CAS, Scopus and Google Scholar

- Research which is freely available for redistribution 